\title{
STUDENTS' ATTITUDES TOWARDS USING SOCIAL MEDIA IN TEACHING FASHION DESIGN COURSES AS ONE OF THE BLENDED EDUCATION METHODS TO ACHIEVE SUSTAINABLE DEVELOPMENT
} Mirhan Faraj ORABI *

Department of Apparel and Textile, Faculty of Home Economics, Helwan University, Egypt

\begin{abstract}
In light of what the world is witnessing today of a great technological boom in information and communication technology, and the resulting tremendous developments in educational technology, patterns of education based on that technology have emerged, e-education and distance education using the Internet with many variations. Within the framework of researchers interested in developing teaching and learning methods, a good pattern has emerged known as blended learning, and blended education has become the focus of attention of many educators, academics and those responsible for education in most countries of the developed world.

Keywords

Students' Attitudes, Social Media, Teaching, Fashion Design, The Blended Education, Sustainable Development.
\end{abstract}

\section{Introduction}

where (Ammar 2010) confirms that blended education improves educational quality and gives learners A set of technological options that enable them to follow the progress of the educational process. (Al-Ghamdi 2002) also indicated that blended education helps to provide learners with flexibility and focuses on learning to be interactive and not by indoctrination. Whereas (2003 Singh) describes blended learning as diversifying methods of content delivery (the training program or course with the aim of increasing the effectiveness of targeted learning outcomes while reducing the cost of delivering that content. Examples of teaching, teaching and content delivery methods that can be used together, all or some of them, in education are examples Integrated teaching is face to face, e-learning in the presence of a teacher or coach, live-learning, and self-education according to the speed and conditions of the learner (Valiathan 2002) (self-paced learning), and there are many points of view in defining blended learning and defining what it is, as some claim that it is merging Several methods of teaching inside the classroom, while others claim that it combined several methods of teaching inside and outside the classroom, regardless of whether those methods use technology or not (especially internet technology). In general, the concept of blended education is not a new concept, as it is the result of many innovations in the field of teaching and learning in many countries of the world. But what makes this concept acquire new dimensions is the entry of information technology using the Internet in this field and the entry of distance education into the equation, but it has become

* Corresponding author: homeecon@helwan.edu.eg 
widely agreed that the concept of blended education means integrating the teaching method face to face, with distance education using the Internet. These two styles have many variations. Blended learning is used because of its many benefits, the most important of which is combining the advantages of face-to-face education, including the development of skills, interaction, communication, and working in a team, developing the ability to observe and use laboratories and their equipment and between distance education using the Internet, as this achieves the flexibility of appointments for each teacher And the learner, and the possibility of accessing many resources available on the information network without the need for high-tech technology inside the classroom, and the possibility for each student to learn the appropriate rhythm for his abilities and personal skills, including the reduction of costs in general for the learner and for the organization organizing the educational or training program alike. This is in line with the fourth goal of the 2030 Sustainable Development Goals set by the United Nations, which is "to ensure quality, equitable and inclusive education for all and to enhance lifelong learning opportunities for all, as blended education provides greater opportunities for lifelong learning continuity, as it opens new forms and patterns of education. Teaching and learning methods that provide greater opportunities for girls who are marginalized or deprived of access to education because of the geographical environment or not Social or economic conditions because it is very low-cost education compared to other forms of education, and it does not require the dedication or presence required by the traditional form of face-to-face education, which makes it a strong candidate for spread as a solution to many problems that hinder the education of the most needy groups and lifelong learning while Many universities in the world use Learning Management Systems LMS to communicate between professors and students. Reality imposes itself on the scene, as social networking sites have revolutionized the way individuals interact, communicate and exchange information. Social networking sites are interactive networks for social communication via the Internet that allow its users to communicate at any time and anywhere in the world with individuals, groups or institutions so that communication between them takes place. They can also visual and audio communication, exchange pictures, and other capabilities that strengthen social relations between them, as well as contribute to exchanging opinions and strengthening friendships (Mr. and Mohammed 2012). Facebook is the most popular and used network in the world, followed by a number of networks such as Twitter Twitter and MySpace.

However, the official use of these sites in education has not received a large amount of empirical research that measures the effectiveness of using these sites in education as a guide or assistant to learning management systems and how to employ these sites in teaching and 
learning activities, and many studies have shown that the majority of students use communication sites. Social media, in particular Facebook, to discuss some scholarly matters and exchange scientific and study materials between them, but at the same time they do not much prefer communicating with their professors through these sites, and some scholars suggest the necessity of using social networking sites, especially "Facebook" between professors and students. This creates an intimate atmosphere and a more comfortable and convenient learning environment.

In view of the current reality of teaching courses in many Egyptian public universities, we find that universities do not adhere to a specific strategy for communication between professors and students in various courses using LMS systems of any kind despite their presence in almost all universities. In contrast to the situation in many private and foreign universities in Egypt, which oblige students and professors to communicate officially using one of the learning management systems, the use of such systems in Egyptian public universities is optional and is left to the ability of the professor and the faculty's capabilities and many other factors that cannot be mentioned here.

Despite the difficulty of using LMS in many government colleges in Egypt, communicating with students through social media remains a rejected choice for many professors and college administrations alike as an informal way to communicate with students, but in light of the unprecedented development in information technology, And new generations of students owning such modern technology, especially smart phone technology and its applications, regardless of the student's economic and social level. The researcher saw experimenting with using some social media sites in teaching some fashion design courses instead of using the learning management system provided by the university, which requires its use by many One of the complex procedures and preparations for the professor and students alike, and that application is the method of blended learning with the simplest and most accessible capabilities for students, and then measuring students 'attitudes in an Egyptian university, which is Helwan University, and one of the applied specializations, which is the specialization of clothing and textiles at the College of Home Economics, towards using this method in preparation for the recommendation Using it or not, and considering the possibility of it being considered an official way to just connect. The research problem can be formulated in the following questions What is the role of social media in blended learning? What is the impact of this on sustainable development? .

What are the students' opinions and attitudes towards using social networking sites (Facebook 
as a model) in teaching fashion design courses? .

- Is there a relationship between students 'opinions and attitudes toward using Facebook in teaching fashion design courses and the professor's interaction with students on Facebook in those courses?

Is there a relationship between students 'opinions and attitudes toward using Facebook in teaching fashion design courses and their readiness to use it?

Does the student's privacy be affected by using Facebook for educational purposes? Does this affect students 'tendency to use Facebook in blended education?

\section{Theoretical framework:}

First: The role and trends of students towards the use of social networking sites in blended education, and its impact on sustainable development:

Facebook is the most used social networking site in the world. The intensity of its use is due to many reasons and features that are not available to others collectively as in Facebook, the most important of which is that it is compatible with all types of devices and operating systems, which makes entering a personal account from any device and from anywhere in the world easy, and creating an account A very easy process with the ability to create multiple forms of accounts according to the type of activity required (individuals - institutions - bodies commercial ... etc.) for free while preserving privacy as much as possible, and many other privileges that made Facebook the most popular communication site Around the world and in the field of education, the use of Facebook has provided many possibilities, whether at the level of communication between the professor and students, or students and each other, or at the level of displaying and circulating educational materials and discussing many matters related to a course or a study project with unprecedented ease, as it does not need Use it to train.

\section{Advantages and disadvantages of using Facebook in blended learning:}

Although many studies that in the past dealt with the use of social networking sites in education, especially Facebook, had focused on its negative effects rather than its positive effects, as those studies linked the time students spend using Facebook with lower levels of achievement and performance. Among students, however, the increasing use of social networking sites in recent years has prompted researchers to try to test the possibilities of using these sites to support the educational process.

One of the most important benefits of using Facebook for students is that they can obtain the educational material for the lessons and supporting materials and circulate them easily. Students and teachers alike emphasized that the use of social networking sites achieved an increase in communication, social relations and group affiliation among them, which made 
them enjoy more learning. And they see it as educated activists.

These results are consistent with the results of a study (2008 Ellison) entitled "Reshaping Communication within the Campus Community through Social Media Sites", which confirmed that Social Networking Technologies (which is represented by the use of social networking sites, including "Facebook", was one of The positive forces that helped facilitate student interaction while teaching courses at the university in which the study was conducted, as students organize study groups and work teams to accomplish the study projects required of them, write laboratory reports, in addition to organizing recreational and sports activities between them.

A study (2013 Bicen \& Uzunboylu) entitled "The use of social networking sites for learning confirms the Facebook case study" which aimed to explore the positive aspects of using Facebook, as well as a survey of teachers' opinions about this matter, which was applied to a sample of school students and teachers. - Emphasizes that when Facebook is used for educational purposes, teachers are more positive towards it, as this enables them to implement many activities and provides them with many capabilities that are not easily available in the classroom. The teachers stated that the virtual learning environment via Facebook improves the Teamwork skills and students 'learning skills in general. The study recommended the use of Facebook in education. The study itself also confirms that the use of Internet technology has facilitated the process of communication between students and teachers and between students and each other, and has provided the opportunity for many activities that are difficult to implement within Study limit such as sharing photos, videos and various files.

These results confirm the study (2016 Elamrousy) entitled "The Function of Social Networks" Facebook "in E-Teaching According to QM Standards and Its Impact on the Development of Creative Thinking Skills of an Aware of King Khalid University Students", where the researcher explained a number of advantages of using Facebook in education from The most important of them are: Helping learners through Facebook to create, innovate and free learning according to their desires and abilities Providing and providing opportunities for cooperative and interactive learning among students and developing self and individual learning Helping learners to participate in the production of educational material and enhancing posts with immediate feedback Activating social learning processes among a group of learners to achieve educational goals For the entire course, activation of modern teaching strategies such as active learning and e-learning, to increase learners' motivation towards learning and the development of creative thinking skills. 
While the negatives of using "Facebook" the acquirer in the educational process were limited to the weakness of internet networks in some residential areas in which students live, technical breakdowns for students' access to Facebook pages, the absence of human interaction between the student and the teacher face to face, and we can conclude from the foregoing that education using the means Social communication provides an opportunity for continuous learning for students after graduation, and for non-specialists who want to learn and social, economic or geographical conditions prevent them from enrolling in formal education or training courses. This also provides equal and fair opportunities for learning for all groups. It also reduces the consumption of resources needed for education through methods. The traditional face-to-face saving of time, effort, means of transportation, logistical equipment and the costs involved in all of that, which leads to the achievement of the 2030 Sustainable Development Goals.

\section{Results:}

To verify the assumptions of the current research, the trend scale was designed to survey students 'opinions and measure their attitudes towards using social networking sites (Facebook as a model) in teaching fashion design courses. The following results were reached:

\section{Discussion:}

In the following, the results that have been reached will be discussed and interpreted in order to link them to the theoretical framework of the research and then answer the research questions.

Discussing the results of the first hypothesis: "Students' opinions and attitudes are positive towards using social networking sites (Facebook» as a model) in teaching fashion design courses.

It is evident from the results of the first hypothesis that the general trend of students was positive towards using Facebook in teaching fashion design courses, as the most frequent values (the mode) are the positive trend, and the mediator also falls in the positive direction, especially since the survey questions contain inquiries. On the extent to which the student benefits from using Facebook as an educational method, and the extent of his conviction that "Facebook" is a useful and good educational tool and method.

Based on the above, and by retrieving what was stated in the theoretical framework about the role of social networking sites in blended education, it is possible to answer the first deliberation of the current research, namely: "What is the role of social media sites in blended education? And what is the impact of that on sustainable development?" She confirmed the results of the current research - in agreement with the results of previous studies. Social networking sites ("Facebook as a model) have an important role in applying the blended 
learning method in teaching fashion design courses at the lowest possible cost and the simplest capabilities available to almost everyone. Students and professors alike can use Facebook instead of LMS learning management systems, which is what It fits the conditions of the teaching and learning environment in our public universities in the Arab Republic of Egypt in light of the lack of resources, and is particularly suited to the conditions of the teaching and learning environment in the clothing and textile department of the Faculty of Home Economics, Helwan University. It also provides an opportunity for continuous learning for students after graduation, and for non-specialists who wish In learning fashion design skills, and social, economic, or geographical conditions prevent them from enrolling in formal education or training courses. This also provides equal and fair learning opportunities for all groups. It also saves from the consumption of resources needed to teach using traditional face-to-face methods such as saving time, effort, transportation, logistical equipment and expenses. The consequences of all this are conducive to achieving the 2030 Sustainable Development Goals. The results of the current research on this point are consistent with the results of Studies that highlighted the advantages and disadvantages of using Facebook in education.

- It is also possible, by discussing the results of the first hypothesis, to answer the second question of the current research, namely: "What are the opinions and attitudes of students towards using Facebook to teach fashion design courses? Where the results of the current research are clear - in agreement with the results of previous studies as well?" The students 'opinions and attitudes towards using Facebook in teaching fashion design courses in general are positive, and although students have affirmed their preference for face-to-face communication in teaching art in general, their views on using Facebook" to communicate for complementary purposes in order to bridge the gaps in The face-to-face teaching method was generally positive opinions. The students 'opinions showed that the advantages and disadvantages of using Facebook in teaching fashion design courses that the students felt in the current research are the same advantages and disadvantages mentioned in previous studies such as speed of communication and ease of exchange of information and study materials. Especially photos and videos, the difficulty of communicating in the event of a disconnection on the Internet, the students' preoccupation with side interactions between each other on the margins of their interaction with regard to learning, and the consumption of more time than abhorrence Trauma. Some students, members of the sample, added in the current research some advantages and disadvantages that were not mentioned in previous studies, including, for example: 


\section{- $\quad$ Features:}

A- Giving many exercises on the test questions, "The professor corrects us our written answers and thus learns the correct answer that we must write in the test." He explains to me what I did not pay attention to during the lecture, "I can refer to the notes that the professor writes on Facebook Facebook »More than once, this helps me focus and study better.“ The teacher puts instructions for us to do home and group assignments on Facebook, and that helps us not to forget these instructions and follow them carefully. "

B- Defects, "Sometimes some students deny wrong information and I read it before the professor corrects it, and thus the information proves to me the wrong and it becomes difficult to correct it in my mind." "Some students steal my effort and heat it up as it is and present it in their name. One of us is the cheater. "Sometimes I cannot work and send the assignment except at the last moment, and I need to comment and correct the professor, but she is not available at all times, "I feel that the professor is losing her identity because she is with us on Facebook." Difficult to reach, "I feel ashamed in front of my colleagues when the teacher corrects me my mistakes."

\section{Conclusion:}

This research sought to shed light on the role of blended education in achieving sustainable development, while clarifying the importance of using social networking sites in teaching as one of the methods of blended education in general and in teaching fashion design courses in particular, highlighting the possibility of considering this method as one of the means by which It can be promoted to the official level of communication between the student and the professor, and for that, the current research followed the descriptive approach in measuring the opinions and attitudes of students towards using Facebook to teach fashion design courses, by applying it to a deliberate sample of 110 students from the second and third year students in the department. Clothes and textiles at the Faculty of Home Economics, Helwan University, in the children's fashion design course for the second year, and the women's fashion design course for the third year, and the research found that students 'opinions are generally positive towards blended education using social networking sites, as well as the existence of a correlation relationship. Strong positive, which is a statistically significant relationship between the opinions and attitudes of students in general towards the use of social networking sites to teach fashion design courses Among a number of factors that previous research and studies have mentioned affect students' attitudes towards blended education using social networking sites. Among the most important of those factors, which the current research has proven to have a strong positive correlation with statistical significance, with students 'attitudes in the current 
research separately, are:

1- The extent of the professor's interaction with students on social media for educational purposes.

2- The readiness of students to use social networking sites in blended education.

3- The extent to which the student's privacy is preserved during interaction on social media for educational purposes. We conclude from this that it is necessary to take advantage of social media sites in teaching in general and in teaching fashion design courses, especially because they provide an active, inexpensive and easy-to-use virtual learning environment available to almost everyone, which raises From the effectiveness of education, which contributes to achieving the goals of sustainable development, as education using social media provides an opportunity for continuous learning for students after graduation, and for non-professionals who want to learn fashion design skills, and social, economic or geographical conditions prevent them from enrolling in formal education or training courses. This also provides equal and fair opportunities for learning for all groups. It also reduces the consumption of resources required for face-to-face traditional methods of education, such as saving time, effort, means of transportation, logistical equipment, and the resulting expenses, which is conducive to achieving the 2030 Sustainable Development Goals.

Research recommendations:

1- Spreading the culture of using the methods and means of integrated education in our educational institutions and its impact on sustainable development.

2- Conducting research to measure teachers 'attitudes towards using Facebook in blended education.

3- Conducting experimental studies and research to measure the effect of independent variables in the current research on students 'achievement level.

4- Conducting studies and research on a large scale and on large numbers of students from various cultural, educational and social backgrounds to measure the extent of the impact of using Facebook for educational purposes on students' privacy and the type of that effect, and the extent to which it relates to students 'attitudes towards using social media in blended education in order to determine the type The form of correlation between the two variables.

5- The possibility of using Facebook in a manner that rises to the level of "official dealings between the teacher and students, if the rules for dealing were established from the beginning and the instructions recommended by previous studies conducted in this area were followed." 6- The necessity to take into account the conditions of the teaching and learning environment 
when determining teaching methods and when designing educational activities.

7- The importance of carefully designing teaching and learning activities before starting to apply blended learning methods

\section{References:}

1- Immediately, c. a. s. (2012). E-learning and its tools. I 1. Dammam: Al-Mutanabi Library.

2- Al-Rantisi, M. M. (2016). The effect of using blended learning and hypermedia on the cognitive achievement and acquisition of digital photography skills among students of journalism at the Ummah University in Gaza. The Islamic University Journal for Educational and Psychological Studies. Volume 23. Issue 1.

3- Mr., M. a. a. (2015). Social media networks and their impact on the ethical values of university youth groups. Journal of Social Work (Egyptian Association of Social Workers). Issue 54. Pp. 15-67.

4- Al-Ghamdi, kh. P. M. (2007). Author learning, fifth year. Issue (53)

5- Siddiq, M. P. (2001). General Education, the Challenges of the Century and the Challenges of the Twenty-first Century, Annual Scientific Conference of the Faculty of Education at the University of Khartoum.

6- Ammar, M. (2010). The Effectiveness of Using Blended Learning in the Development of Cognitive Achievement and Visual Imagination in Electrical Engineering for First Year Secondary Industrial Students and their Attitudes Toward it, The First International Conference, Blended and Mobile Learning, Possibilities and Challenges, Omani Association for Education Technology.

7- Alajab, M., \& Hussain, A. M. (2015). The impact of a blended learning course on Khartoum University students's achievement and motivation to learn scientific English. American International Journal of Social Science, 4 (2), 132--158.

8- Ali, N., Kay, H.-C., \& Ryan, M. (2004). Students' Perceptions of Online Learning Implications for Teaching. Nurse Educator, 29 (3).

9- Allen, I. E., Seaman, J., \& Garrett, R. (2007). Blending in: The Extent and Promise of Blended Education in the United States. Sloan Consortium.

10- Banerjee, G. (2011). Blended Environments: Learning Effectiveness and Student Satisfaction at a Small College in Transition. Journal of Asynchronous Learning Networks, 15 (1), 8--19.

11- Bicen, H., \& Uzunboylu, H. (2013). The Use of Social Networking Sites in Education: A Case Study of Facebook (Vol. 19).

12- Bonk, C. J., \& Graham, C. R. (2012). The Handbook of Blended Learning: Global 
Perspectives, Local Designs. John Wiley \& Sons.

13- Ellison, N. B. (2008). Reshaping campus communication and community through social network sites. In The ECAR study of undergraduate students and information technology (pp. 19--32). EDUCAUSE Center for Applied Research.

14- Elmarousy, N. (2016). Employment of "Facebook" social networking in the E-Teaching in accordance with the standards of the QM and its impact on the development of creative thinking skills A sample of Female students at King Khalid University. International Journal for Research in Education, 40 (1), 105--139.

15- Epure, M., Mihaes, L., Gray, F., \& Baicu, C. (2015). Blended learning in Higher Education: a view from within. In Proceedings of the 8th International Conference of Education, Research and Innovation.

16- Erdem, M., \& Kibar, P. N. (2014). Students' Opinions on Facebook Supported Blended Learning Environment. Turkish Online Journal of Educational Technology - TOJET, 13 (1), 199-206.

17- Franks, P. (2002). Blended Learning: What is it? How does it impact student retention and performance? (pp. 1477--1480). Presented at the ELearn: World Conference on E-Learning in Corporate, Government, Healthcare, and Higher Education, Association for the Advancement of Computing in Education (AACE).

18- Jones, N., Blackey, H., Fitzgibbon, K., \& Chew, E. (2010). Get Out of MySpace! Computers \& Education, 54 (3), 776--782.

19- Kabilan, M. K., Ahmad, N., \& Abidin, M. J. Z. (2010). Facebook: An online environment for learning of English in institutions of higher education? The Internet and Higher Education, 13 (4), 179--187.

20- Kirschner, P. A., \& Karpinski, A. C. (2010). Facebook® and Academic Performance. Comput. Hum. Behav., 26 (6), 1237--1245.

21- Mason Mohamed Ahmed ISMAIL, Zainab Abdel Hafeez FARGHALY, Azizah Ahmad Muhammad AL-AQLI, EFFECTIVENESS OF TRAINING PROGRAM FOR BASICS OF SEWING TECHNIQUES FOR WOMEN IN NORTH SINAI, International Journal of Education and Learning Research, Vol. 1, No. 1, 2018, pp. 33-41.

Received: July 9, 2018

Accepted: September 17, 2018 